This is an author-archived preprint version of the article, as permitted by Elsevier's author rights policy. The final, definitive version of the article was published in Applied Ergonomics as

Lockton, D., Harrison, D.J., Stanton, N.A. 'The Design with Intent Method: a design tool for influencing user behaviour'. Applied Ergonomics Vol.41 No.3, pp. 382-392, May 2010, http://dx.doi.org/10.1016/j.apergo.2009.09.001

\title{
The Design with Intent Method: A design tool for influencing user behaviour
}

\author{
Dan Lockton a, ${ }^{\mathrm{*}}$, David Harrison ${ }^{\mathrm{a}}$, Neville A. Stanton ${ }^{\mathrm{b}}$ \\ ${ }^{a}$ Cleaner Electronics Research Group, Brunel Design, School of Engineering \& Design, Brunel \\ University, Uxbridge, Middlesex, UB8 3PH, UK \\ ${ }^{b}$ Transportation Research Group, School of Civil Engineering \& the Environment, University of \\ Southampton, Highfield, Southampton, Hampshire, SO17 1BJ, UK
}

\begin{abstract}
Using product and system design to influence user behaviour offers potential for improving performance and reducing user error, yet little guidance is available at the concept generation stage for design teams briefed with influencing user behaviour. This article presents the Design with Intent Method, an innovation tool for designers working in this area, illustrated via application to an everyday human-technology interaction problem: reducing the likelihood of a customer leaving his or her card in an automatic teller machine. The example application results in a range of feasible design concepts which are comparable to existing developments in ATM design, demonstrating that the method has potential for development and application as part of a user-centred design process.
\end{abstract}

Keywords: Product design, interaction design, user behaviour, methods

\section{Introduction}

\subsection{Designer intent and influencing behaviour}

Stanton and Baber's 1998 editorial for this journal, 'Designing for Consumers' (Stanton \& Baber 1998a) begins with the notion that " $[\mathrm{t}]$ here are varying degrees of success to which the designers' intentions regarding product use are realised. In designing products, designers are also designing user activity, which does not occur independently of the product." It goes on to note that "[i]n some way, consumer behaviour is shaped by products as much as products are shaped by consumer behaviour." 
Much human factors work on improving system performance by reducing user error (e.g. Baber \& Stanton 1996) and interaction design in general is effectively about influencing user behaviour, even if rarely recognised as such (e.g. Kolko 2007). Herbert Simon's assertion that "everyone designs who devises courses of action aimed at changing existing situations into preferred ones" (Simon 1969) applies to designing behaviour as well as physical features: indeed, the concept of design explicitly intended to influence users towards particular behaviours recurs across a number of disciplines, from urban planning to reduce crime (e.g. Katyal 2002) to human-computer interaction (e.g. Beale 2007).

However, little work has been done to link ideas and techniques from these disparate fields, identify common themes, and present them in a form which can be applied during the design process to develop new products and systems, and improve existing ones. While there is growing recognition that "designers are in the behaviour business" (Fabricant 2009), there is little general guidance available for design teams briefed with influencing user behaviour, particularly in contexts where social benefit would result: this facet of the design process is not explicitly covered by the variety of ergonomics tools available to designers (Stanton \& Young 1998). As Blevis (2007) puts it (in the context of influencing more sustainable user behaviour), "[i]t is easier to state the kinds of behaviours we would like to achieve from the perspective of sustainability than it is to account for how such behaviours may be adequately motivated." While in some specific domains, 'how-to' guides have been evolved, (e.g. Crowe 2000 in architectural design against crime; Grout 2007 in medical design errorproofing; Chak 2003 in persuasive website design), there are no cross-domain guides applicable by designers working on 'new' problems, or new ways of addressing existing user behaviour problems.

The Design with Intent Method, introduced in this article, aims to address this deficiency, suggesting relevant design techniques for influencing types of behaviour, and providing examples of how similar problems have been tackled elsewhere. Defining 'Design with Intent' (DwI) as 'design intended to influence or result in certain user behaviour', the authors have reviewed examples from a variety of disciplines (Lockton et al 2008a, 2008b), supported by a blog website and more recently an ongoing survey of designers, receiving comments, suggestions and examples from readers around the world, and incorporated this analysis into a tool for designers.

\subsection{Background: perspectives on influencing user behaviour}

Three presuppositions underpin the DwI research: (i) If certain design techniques have effects on user behaviour unintentionally, the techniques could also be applied intentionally; (ii) Differences in design approach between environments, products (hardware/software) and services largely are due to disciplinary boundaries rather than innate incompatibility—all are designed systems, and many techniques, or analogues of them, recur across multiple fields of application; and (iii) It is therefore possible to abstract certain techniques from examples in one field, and use them in others, following Hendrick's (2008) argument that "the HSIT 
[human system interface technology] used in the designing of one system, product or built environment can be applied to other, very different ones."

Examples of DwI in design, human-computer interaction (HCI) and architecture are often based on environmental and ecological psychology, from behaviour settings (Barker 1968; Sommer 1969) to Gibson's affordances (1986), extended by Norman $(1988,1999,2008)$ and others (Gaver 1991, 1992; McGrenere \& Ho 2000). In parallel, the development of error-proofing, from Shingo's (1986) poka-yoke manufacturing quality control to the design of healthcare processes (Grout 2007; Design Council et al. 2003; Lane et al 2006) has promulgated often affordance-based techniques (Beatty 2008) within organisational policy. Diverse practitioners are thus aware of the strategic use of affordances as 'interventions' influencing user behaviour, from forcing functions reducing vehicle misfuelling (Adams \& David 2007) to councils preventing the homeless sleeping on benches (Lockton 2005).

In behavioural economics, the 'heuristics and biases' approach pioneered by Kahneman et al (1982) has recently taken a high-profile turn (Cialdini 2003; Ariely 2008; Thaler \& Sunstein 2008) towards influencing behaviour, and awareness of this approach among human factors practitioners appears to be increasing, e.g. Seva et al's (2007) use of the affect heuristic (Slovic et al. 2002) and a recent lead article in The Ergonomist (Richardson 2008). It is therefore desirable that design methods for influencing behaviour include a treatment of these principles, in a form useful to designers looking to apply them.

Persuasive Technology (Fogg 1999, 2003) applies elements of rhetoric (Kjaer Christensen \& Hasle 2007) and conditioning to influence behaviour, mainly (so far) in the context of social networking websites and mobile computing. This is one of the main bodies of current work pertinent to the DwI concept, but the criterion of persuasion - requiring attitude change as a precursor to behaviour change-excludes situations where attitude change is not required for changes in behaviour, especially in safety systems, where the designer does not necessarily care whether a user's attitude changes towards a behaviour, simply that the behaviour itself changes. The interlock on a microwave oven preventing operation with the door open influences user behaviour successfully without explicitly 'persuading' users of the need to operate the device safely, though that may also be a parallel effect.

It has been argued (Buchanan 1985; Redstrom 2006) that all design is intended to influence user behaviour, in the sense that the artefacts around us contain socially constructed 'scripts' for users (Akrich 1992) - e.g. if we position a chair at a workstation, we are influencing a user to 'follow the script' and sit down. Nevertheless, systems intentionally designed to influence behaviour different from that usually associated with the situation, or in situations where a user would not otherwise have a strong idea of what to do (e.g. with an unfamiliar interface), represent a degree of designer intent beyond this. Any such products will, of course, always be used within a context involving users' own intentions: emergent behaviours, intuition (Blackler et al 2009), 
appropriation (Salovaara 2008) or prior experience (Chamorro-Koc et al. 2008) mean that designers' intended use (or usability) is not always translated into user behaviour. The task-artefact cycle (Carroll et al. 1991) suggests that new artefacts will coevolve with behaviours (Walker et al. 2009), in turn offering new possibilities. Equally, as Kanis (1998) shows, users operate the same products in many ways and still achieve the desired results. In some fields, such as security or health and safety, user adherence to intended behaviour is more critical than in others-as Cairns \& Cox (2008) put it, "in safety critical systems, like air traffic control or medical monitors... the cost of failure is never acceptable."

\subsection{Scope of application: reducing environmental impact of product use}

The DwI Method has been developed primarily in response to the need of influencing user behaviour to reduce the environmental impact of products which consume resources during use: helping people use products and systems more efficiently. Users' behaviour and operational decisions can contribute significantly to environmental impacts (Elias et al. 2007; Wood \& Newborough 2003; McCalley \& Midden 2002), and the UK Government's Stern Review (Stern 2007) identifies behaviour change as a priority in this field. Some design researchers (Lilley et al. 2005, 2006; Elias et al. 2007; Lockton et al. 2008b, 2009b; Wever et al. 2008; Rodriguez \& Boks 2005; Bhamra et al. 2008) have begun to develop the field of 'design interventions' applicable by designers as responses to user behaviour 'problems', particularly environmental, but also 'prosocial' behaviour generally. Within the ergonomics community, this work begins to answer the call of Flemming et al (2008) for the application of human factors expertise to 'the sustainability domain'.

Nevertheless, the DwI Method is intended to be generally applicable to influencing user behaviour, including but going beyond the ecodesign field; this paper thus illustrates its potential by application to an everyday human-technology interaction problem: reducing the likelihood of a customer leaving his or her card in an automatic teller machine (ATM). 


\section{The Design With Intent Method}

The starting point of the DwI Method is the existence of a product, service or environment - a system — where users' behaviour is important to its operation, or where it would be strategically desirable to alter the way it is used. The goal of the design process is to modify or redesign the system to achieve this: to influence users' behaviour towards a particular 'target behaviour'. The method is a 'suggestion tool', inspiring design solutions by suggesting techniques, with examples applicable to particular target behaviours. These target behaviours have been inferred from assessing examples from different disciplines (section 1.2) and are by no means definitive or complete: they are simply an aid to selecting a useful subset of techniques: a range of ways to address the brief, which can be developed into concepts and assessed further against the project criteria. While the DwI Method cannot replace the domain expertise, insight or creativity which experienced professionals can bring, it is intended to assist in exploring responses to a brief and allow designers to benefit from others' work on analogous problems. Throughout, the aim has been to make any work of direct relevance and immediate use to designers in the context of real projects and briefs rather than theoretical development from first principles, hence a 'design pattern' method, after Alexander et al (1977) and Tidwell (2005), was considered appropriate.

\subsection{Overall structure}

The general structure of the method is shown in Figure 1: there are two 'modes', inspiration and prescription, depending on how the designer or design team prefers to make use of it.

\section{[Figure 1 about here please]}

\subsubsection{Inspiration mode}

In inspiration mode, the designer takes inspiration from a set of 'headline' design patterns which are applicable to a wide range of target behaviours, grouped into six different 'lenses' (section 2.2) representing particular disciplinary perspectives on using design to influence behaviour. The patterns, illustrated with examples from different fields, serve as a creative trigger. The use of illustrated examples in an 'idea space' is intended to allow designers to understand the patterns quickly, even where the terminology is unfamiliar. Figure 2 shows the 'toolkit' poster (Lockton et al 2009a) produced for use in workshop sessions and made available online as a reference for designers, together with a detail view of one of the headline patterns from the Cognitive lens, Social proof.

[Figure 2 about here please] 


\subsubsection{Prescription mode}

In prescription mode, the designer formulates the brief in terms of one of a range of target behaviours (section 2.3), describing interactions; for each target behaviour, a subset of the most applicable design patterns from each lens is presented, again illustrated with examples, the number varying depending on the target behaviour, but typically 15-25 applicable patterns. While still serving as a creative inspiration, this mode effectively 'prescribes' a set of patterns which are especially applicable or have been applied to similar problems by other designers, in other contexts. Each pattern is described and the advantages and disadvantages discussed with notes on its implementation, user reactions and effectiveness.

From the prescribed patterns, a range of design concepts can be generated, all of which have at least some 'precedent' in terms of the underlying patterns' application in behaviour change contexts. The form of the prescription mode, loosely modelled on TRIZ (Altshuller 1996) — which has been developed and applied in errorproofing (Grout 2007) and ecodesign (Jones et al. 2001; Craig et al. 2008)-leads the designer from a specific brief to a more general brief (the target behaviour), and general solutions (the suggested patterns) then serve as the model for specific solutions to the original brief. The reality of most design processes is that constraints, whether financial, political, or legal issues, development time, domain expertise or organisational strategies will make many patterns difficult to apply, but even a few patterns and examples can inspire a range of concepts. (Figure 4 in section 3.2.3 shows some of the design patterns, presented in the form of 'method cards' along the lines of IDEO (2003), prescribed for a particular target behaviour.)

\subsubsection{Evolution of the Method}

The DwI Method has been developed through a series of workshop sessions, mainly with design students and recent graduates (Lockton et al 2009b), testing the usability and utility of the method by applying it to briefs including: influencing reduced use of household lighting; reducing wasted paper and ink/toner in home and office printing; influencing people not to leave bathroom taps running while brushing their teeth; encouraging householders to close curtains at night to conserve heat; reducing unnecessary overfilling of electric kettles; and encouraging continued participation in an online learning system. These sessions have resulted in an evolution of the form and structure of the method, from a procedural tree, through various kinds of 'idea space' diagrams, with different classification schemes for the design patterns and target behaviours. The division into inspiration and prescription modes was introduced as a result of observing how different participants worked with the briefs they faced (Lockton et al 2009b). The workshop sessions have also compared the relative effectiveness of the inspiration and prescription modes in terms of the numbers, variety and relevance of concepts produced by participants working individually and in teams.

\subsection{Six 'lenses' on influencing user behaviour}

The six lenses (Table 1) are a way of grouping design patterns which share similar considerations, behavioural understanding or assumptions about how to influence users: to some extent, these groups-Architectural, 
Errorproofing, Persuasive, Visual, Cognitive and Security—resolve into particular 'worldviews', the way that a designer versed in a particular discipline might approach a brief on influencing behaviour.

Table 1. Six 'lenses' on influencing user behaviour

\begin{tabular}{|c|c|}
\hline Architectural lens & $\begin{array}{l}\text { The Architectural Lens draws on techniques used to influence user behaviour in } \\
\text { architecture, urban planning and related disciplines such as traffic management } \\
\text { and crime prevention through environmental design (Crowe 2000; Katyal 2002; } \\
\text { see also the Security lens). While the techniques have been developed in the built } \\
\text { environment (e.g. Alexander et al. 1977), many ideas can also be applied in } \\
\text { interaction and product design, even in software or services; they are effectively } \\
\text { about using the structure of systems to influence behaviour. }\end{array}$ \\
\hline Errorproofing lens & $\begin{array}{l}\text { The Errorproofing Lens treats deviations from the target behaviour as 'errors' } \\
\text { which design can help avoid, either by making it easier for users to work without } \\
\text { making errors, or by making errors impossible in the first place (Shingo 1986; } \\
\text { Chase \& Stewart 2002; Grout 2007). This view on influencing behaviour is often } \\
\text { found in health \& safety-related design, medical device design and manufacturing } \\
\text { engineering. }\end{array}$ \\
\hline Persuasive lens & $\begin{array}{l}\text { The Persuasive Lens represents the emerging field of persuasive technology (Fogg } \\
\text { 2003), where computers, mobile phones and other systems with interfaces are } \\
\text { used to persuade users: changing attitudes and so changing behaviour through } \\
\text { contextual information, advice and guidance. }\end{array}$ \\
\hline Visual lens & $\begin{array}{l}\text { The Visual Lens combines ideas from product semantics, semiotics, ecological } \\
\text { psychology and Gestalt psychology about how users perceive patterns and } \\
\text { meanings as they interact with the systems around them, and the use of metaphors } \\
\text { (e.g. Saffer 2005; Barr et al. 2002). }\end{array}$ \\
\hline Cognitive lens & $\begin{array}{l}\text { The Cognitive Lens draws on research in behavioural economics looking at how } \\
\text { people make decisions, and how this is affected by heuristics and biases } \\
\text { (Kahneman et al. 1982). If designers understand how users make interaction } \\
\text { decisions, that knowledge can be used to influence interaction behaviour. Where } \\
\text { users often make poor decisions, design can help counter this. }\end{array}$ \\
\hline Security lens & $\begin{array}{l}\text { The Security Lens represents a 'security' worldview, i.e. that undesired user } \\
\text { behaviour is something to deter and/or prevent though 'countermeasures' } \\
\text { (Schneier 2003) designed into products, systems and environments, both } \\
\text { physically and online, with examples such as digital rights management. } \\
\text { From a designer's point of view, this can be an 'unfriendly' and, in some } \\
\text { circumstances unethical view to take, effectively treating users as 'guilty until } \\
\text { proven innocent'. }\end{array}$ \\
\hline
\end{tabular}

For example, a designer experienced in $\mathrm{HCI}$ or safety engineering may have a repertoire of patterns which take an errorproofing approach, treating deviations from a target behaviour as errors to be prevented or made less likely through the use of defaults, forcing functions and warning alerts, whereas a graphic designer may focus on using visual techniques to influence perceptions. The aim of the lenses is primarily to allow designers to see 'how others might approach a problem', allowing designers to think outside the immediate frame of reference suggested by the brief (or client); the groupings of patterns is not rigorously defined theoretically.

\subsection{Target behaviours}

In prescription mode, the DwI Method makes use of target behaviours: intended outcomes, particular user behaviours, which we want to achieve through design. Target behaviours provide an abstract classification for the intended user behaviour, expressed in terms of a goal. The 'success' of such a design could be measured 
by the extent to which the target behaviour is achieved. Table 2 shows eleven target behaviours identified from real examples, applicable to a range of briefs about influencing user behaviour; there are potentially many more. Each target behaviour maps to a number of potentially applicable design patterns.

\section{Table 2. Target behaviours with examples}

\begin{tabular}{|c|c|c|}
\hline \multicolumn{3}{|c|}{ User-system interaction } \\
\hline S1 & $\begin{array}{l}\text { The user follows a process or path, doing } \\
\text { things in a sequence chosen by the designer }\end{array}$ & $\begin{array}{l}\text { Customer places order via website without missing } \\
\text { out any steps }\end{array}$ \\
\hline $\mathbf{S 2}$ & $\begin{array}{l}\text { The user follows a process or path that's } \\
\text { optimised for those particular circumstances }\end{array}$ & $\begin{array}{l}\text { User only spends as much time as really needed in } \\
\text { the shower }\end{array}$ \\
\hline S3 & $\begin{array}{l}\text { Decision among alternatives: a user's choice } \\
\text { is guided }\end{array}$ & Diners choose healthier meal in office canteen \\
\hline S4 & $\begin{array}{l}\text { Only certain users / groups of users can use } \\
\text { something }\end{array}$ & $\begin{array}{l}\text { Only users who know PIN can access bank account } \\
\text { via ATM }\end{array}$ \\
\hline S5 & $\begin{array}{l}\text { Only users already behaving in a certain } \\
\text { way get to use something }\end{array}$ & $\begin{array}{l}\text { If a driver's travelling below the speed limit, the next } \\
\text { set of traffic lights turn green, otherwise they stay } \\
\text { red }\end{array}$ \\
\hline S6 & $\begin{array}{l}\text { No users can use something in a particular } \\
\text { way, regardless of who they are or what } \\
\text { they've done before }\end{array}$ & $\begin{array}{l}\text { Park bench fitted with central armrest to prevent } \\
\text { anyone lying down }\end{array}$ \\
\hline S7 & $\begin{array}{l}\text { Users only get functionality when } \\
\text { environmental criteria are satisfied }\end{array}$ & $\begin{array}{l}\text { Office lighting cannot be switched on if ambient } \\
\text { daylight adequate }\end{array}$ \\
\hline \multicolumn{3}{|c|}{ User-user interaction } \\
\hline $\mathbf{U 1}$ & $\begin{array}{l}\text { Multiple users are kept separate so they } \\
\text { don't affect each other while using a system }\end{array}$ & Traffic follows one-way system into/out of car park \\
\hline $\mathbf{U} 2$ & $\begin{array}{l}\text { Users (and groups of users) do interact with, } \\
\text { and affect each other while using a system }\end{array}$ & $\begin{array}{l}\text { Staff from different departments mix socially in a } \\
\text { building's atrium }\end{array}$ \\
\hline $\mathbf{U 3}$ & $\begin{array}{l}\text { Users can't block or dominate a system to } \\
\text { the exclusion of others }\end{array}$ & $\begin{array}{l}\text { Wide pedestrian concourses prevent groups blocking } \\
\text { passage for others }\end{array}$ \\
\hline $\mathbf{U} 4$ & Controlled rate of flow or passage of users & $\begin{array}{l}\text { Visitors to popular museum exhibit routed past it } \\
\text { slowly on moving walkway }\end{array}$ \\
\hline
\end{tabular}

Some briefs could be expressed using more than one high-level target behaviour; equally, for a task involving multiple system elements in a process, different target behaviours may apply at different stages: there are, potentially, micro-strategies and macro-strategies. This point is expanded in the ATM example (section 3.2.1).

\subsection{Using the patterns and examples}

Whether using the DwI Method in inspiration or prescription mode, the designer is provided with a range of potentially applicable design patterns and examples, with short explanations, to inspire the generation of concept solutions to the brief. Some patterns may be quickly rejected due to project constraints; others may inspire further investigation, including recollection of other similar examples. Workshop sessions (Lockton et al 2009b) have shown that some participants found it useful to combine two or more patterns to suggest novel approaches to briefs. 


\section{Application: reducing ATM card error}

An example application will illustrate how the DwI Method can be used, in prescription mode (section 2.1.2). This is a simple and quick example, with the brief phrased in one of many possible ways. The choice of an aspect of ATM design is intended as a demonstration of the method, to illustrate how it can be used; ATMs also particularly suitable for analysis using ergonomics methods and concepts, and a number of improved interface designs have been tested by human factors researchers (e.g. Chan et al. 2009; Zimmerman \& Bridger 2000). The behaviour-influencing features of real ATMs, developed in response to user errors over the years, are also easy to compare with the possible techniques suggested by applying the method.

\subsection{Background to the problem}

Automatic teller machines are the face of a product-service system in which user behaviour must be limited to a defined set of permissible interactions, and errors must be designed out. A hierarchical task analysis (HTA; Stanton 2006) of the most common interaction goal, 'Get cash from ATM', for a typical modern ATM is shown in Figure 3. All four plans present (0,1,2 and 3) are either linear 'fixed sequence' or conditional 'contingent sequence' (Ormerod \& Shepherd 2004): the interaction task is strictly limited to a critical path, and the affordances of each element are designed to satisfy this limited path.

\section{[Figure 3 about here please]}

ATMs are intended to replace a human teller, so the interactions afforded by the machine replicate a subset of what is possible in human-to-human interaction, but without the opportunity for intelligent contextual correction of errors. The evolution of ATM design has included measures to reduce error, encouraging user trust in the machines and reducing withdrawal time. Rogers and Fisk (1997) characterised this design goal as being "to ensure that if people wish to use an ATM, the system is designed to enable them to do so efficiently... [A]ccess to convenient and reliable ATMs has become a criterion for choosing a bank, and financial institutions will need to optimize their ATM functions, especially from the perspective of the user."

A full systems analysis (Stanton \& Baber 1998b) including applying Task Analysis For Error Identification (TAFEI; Baber \& Stanton 1994, 1996) would permit a structured prediction of the errors that are possible, but for the purposes of this example, a single type of error, empirically identified, will be discussed. A major opportunity for error with historic ATMs came from a user leaving his or her ATM card in the machine's slot after the procedure of dispensing cash or other account activity was complete (Rogers et al. 1996; Rogers \& Fisk 1997). This was primarily because the cash was dispensed before the card was returned (i.e. a different sequence for Plan 3 in the HTA of Figure 3), leading to a postcompletion error- "errors such as leaving the original document behind in a photocopier... [or] forgetting to replace the gas cap after filling the tank" (Byrne \& Bovair 1997). Postcompletion error is an error of omission (Matthews et al. 2000); the user's main goal 
(Plan 0 in Figure 3) of getting cash was completed so the further "hanging postcompletion action" (Chung \& Byrne 2008) of retrieving the card was easily forgotten.

The obvious design solution was, as Chung and Byrne (2008) put it, "to place the hanging postcompletion action 'on the critical path' to reduce or eliminate [its] omission" and this is what the majority of current ATMs feature (Freed \& Remington 2000): an interlock forcing function (Norman 1988) or control poka-yoke (Shingo 1986), requiring the user to remove the card before the cash is dispensed. Zimmerman and Bridger (2000) found that a 'card-returned-then-cash-dispensed' ATM dialogue design was at least $22 \%$ more efficient (in withdrawal time) and resulted in 100\% fewer lost cards (i.e. none) compared with a 'cashdispensed-then-card-returned' dialogue design. When both cash-then-card and card-then-cash ATM designs were in common use concurrently, there was disagreement among banks as to which design was better for customers (New York Times 1990), since the interlock forcing the user to remove his or her card before receiving cash meant that any desired subsequent transaction would require inserting the card and going through the identification process again - potentially inconvenient. Incorporating a step asking the user about other intended transactions earlier in the process (Zimmerman \& Bridger 2000) largely overcomes this issue.

The current card-then-cash design is now common enough, at least in some countries, for it to be considered ubiquitous and, for example, included exclusively in training programmes on ATM use for new users (Flanagan 2005); the older cash-then-card interaction pattern may provoke comment when users encounter it (Dolan 2005), even in other kinds of public technology such as ticket machines (Lonsdale 2004). Other designs do exist (see section 3.2.4).

Would the DwI Method in prescription mode have suggested the interlock idea? What alternative design techniques might also be applicable? With the brief "We don't want users to leave their cards in ATMs after use", what concepts does the DwI Method suggest?

\subsection{Applying the Dwl Method}

\subsubsection{Target behaviours}

Applying the method in prescription mode (Figure 1), the brief "We don't want users to leave their cards in ATMs after use" is first expressed as a target behaviour (Table 2). The critical interaction path as discussed in section 3.1 suggests that target behaviour S1 is a fit for the brief as an overall macro-strategy- "The user follows a process or path, doing things in a sequence chosen by the designer."

Elements of the ATM and its environment in practice may satisfy different individual target behaviours: security features (such as the card-and-PIN system itself) perhaps satisfy S4 (“Only certain users / groups of users can use something"), as would interaction with a human teller, who may also satisfy S5 ("Only users already behaving in a certain way get to use something") in the sense that if a customer is behaving 
suspiciously, he or she might be denied access. Spacing between adjacent ATMs may satisfy a U1 target behaviour micro-strategy ("Multiple users are kept separate so they don't affect each other while using a system"). Here the brief relates only to users leaving their cards in the slot-a small part of the overall system, but representative of the problem scope designers may be asked to address.

\subsubsection{Suggestion of patterns}

The design patterns suggested for S1 are now consulted (Figure 4), including some from each of the six lenses (section 2.2). In total, 22 applicable patterns are suggested as being relevant; only a few can be shown in detail here.

\section{[Figure 4 about here please]}

At this point, the reader may wish to consider the patterns visible in Figure 4 and how they might be applied to the "We don't want users to leave their cards in ATMs after use" brief. What ideas do they inspire?

\subsubsection{Design concepts inspired by the patterns}

In this article, only a sample can be given of the design concepts inspired by the different patterns, but a few of those suggested by the authors' own application of the process are shown in Table 3 : 
Table 3 Design concepts applicable to ATM problem, inspired by the patterns suggested

\section{We don't want users to leave their cards in ATMs after use}

\begin{tabular}{|c|c|c|c|}
\hline \multicolumn{4}{|l|}{ Architectural lens } \\
\hline Positioning \& layout & Removal & Orientation & Movement \& oscillation \\
\hline $\begin{array}{l}\text { - Change spacing between } \\
\text { interface elements, so that card } \\
\text { slot adjacent to cash dispensing } \\
\text { slot. } \\
\text { - Position card return such that } \\
\text { user's hand passes through space } \\
\text { occupied by card before cash can } \\
\text { be retrieved (see also Interlock / } \\
\text { Lock-in \& Lock-out) }\end{array}$ & $\begin{array}{l}\text { - Remove 'card return' stage of } \\
\text { process entirely, e.g. having user } \\
\text { simply swipe or tap card rather } \\
\text { than leaving it inserted }\end{array}$ & $\begin{array}{l}\text { - Angle card slot directly into } \\
\text { user's field of vision, so more } \\
\text { difficult to miss }\end{array}$ & $\begin{array}{l}\text { - Move card visually to draw } \\
\text { users' attention } \\
\text { - Moving conveyor system which } \\
\text { returns card with cash }\end{array}$ \\
\hline \multicolumn{4}{|l|}{ Errorproofing lens } \\
\hline Interlock / Lock-in \& Lock-out & Conditional warnings & & \\
\hline $\begin{array}{l}\text { - Don't dispense cash until card } \\
\text { has been removed }\end{array}$ & $\begin{array}{l}\text { - Visual or audible alert if card is } \\
\text { still in slot at stage in process } \\
\text { when ought to be removed }\end{array}$ & & \\
\hline \multicolumn{4}{|l|}{ Persuasive lens } \\
\hline Tunnelling & Self-monitoring & Kairos & Reduction \\
\hline $\begin{array}{l}\text {-Wizard, on-screen checklist or } \\
\text { flow-chart indicating what actions } \\
\text { user has taken and needs to take to } \\
\text { complete process correctly }\end{array}$ & $\begin{array}{l}\text { - Provide interface-lights, on- } \\
\text { screen messages, etc- - which } \\
\text { allow user to see the state of the } \\
\text { transaction and where the card and } \\
\text { cash are }\end{array}$ & $\begin{array}{l}\text { - Alerts/messages at exactly right } \\
\text { moment-i.e. when card must be } \\
\text { removed }\end{array}$ & $\begin{array}{l}\text { - Remove need to insert card } \\
\text { entirely-use alternative system, } \\
\text { e.g. RFID or rely on user typing in } \\
\text { card number } \\
\text { - Reduce the number of elements, } \\
\text { so that card is returned with cash }\end{array}$ \\
\hline Simulation \& feedforward & Respondent conditioning & Computers as social actors & \\
\hline $\begin{array}{l}\text { - On-screen display showing user } \\
\text { what to do, e.g. animated } \\
\text { illustration of whole process }\end{array}$ & $\begin{array}{l}\text { - Use messages associating } \\
\text { picking up cash with picking up } \\
\text { card, so that it becomes a habit }\end{array}$ & $\begin{array}{l}\text { - System talks to user and leads } \\
\text { him/her through correct process as } \\
\text { close analogue of human teller } \\
\text { (especially for new users of ATMs } \\
\text { or where new design introduced) }\end{array}$ & \\
\hline \multicolumn{4}{|l|}{ Visual lens } \\
\hline $\begin{array}{l}\text { Implied sequences / Possibility } \\
\text { trees }\end{array}$ & $\begin{array}{l}\text { Prominence \& visibility / } \\
\text { Colour \& contrast }\end{array}$ & Proximity \& similarity & \\
\hline $\begin{array}{l}\text { - Arrange the ATM fascia and } \\
\text { interface so that the interactions } \\
\text { are clearly laid out in the order } \\
\text { they should be used, with optional } \\
\text { paths, etc, clearly indicated }\end{array}$ & $\begin{array}{l}\text { - Simply make the elements which } \\
\text { are important, e.g. the card slot, } \\
\text { very prominent in the ATM fascia, } \\
\text { by size, or using bright / } \\
\text { contrasting colours }\end{array}$ & $\begin{array}{l}\text { - Group together all the elements } \\
\text { with which a user needs to interact } \\
\text { during the process, so that they are } \\
\text { perceived as a single task }\end{array}$ & \\
\hline \multicolumn{4}{|l|}{ Cognitive lens } \\
\hline Authority & Scarcity & & \\
\hline $\begin{array}{l}\text { - Make it very clear that card Must } \\
\text { be removed, via warning messages } \\
\text { / graphics / threats of fines }\end{array}$ & $\begin{array}{l}\text { - Make it imperative not to lose } \\
\text { card by charging penalty fines for } \\
\text { replacement } \\
\text { - Remind user that his/her money } \\
\text { not safe unless card removed }\end{array}$ & & \\
\hline
\end{tabular}

\section{Security lens}

Surveillance

- Use cameras / overt monitoring

to scare / worry user into

removing card, since he/she will

be liable for loss

- Use of cameras / monitoring

(overt or covert) to alert user to

error: "Excuse me, sir/madam,

don't forget your card."

Not every pattern suggested inspired suitable concepts; some inspired very similar concepts; many concepts could work together. These distinctions are useful for the designer since they allow faster convergence to a solution shortlist for each problem. The now-ubiquitous interlock card-then-cash forcing function (section 3.1) is suggested by the method-'Don't dispense the cash until the card has been removed', as are cues such as on-screen displays or lights adjacent to the card slot imploring card removal. These too are present on many 
current ATMs (Chung \& Byrne 2008). In some territories, the 'Having the user simply swipe the card rather than leaving it inserted' design is found (Daily WTF 2008) — a variant is having the user insert and remove the card before starting the transaction (Figure 5; New York Times 1990). RFID-enabled ATM cards are common in some parts of the world (with corresponding security fears from customers; Slashdot 2006) although contactless card readers as part of ATMs are not yet widespread.

\section{[Figure 5 about here please]}

Moving the card slot and cash dispensing slot to be adjacent, or combining return systems are appealing concepts but may require significant redesign of the ATM itself rather than simply interface changes. Nevertheless, as ATMs' functionality expands to include advertising and other transaction services (Williamson 2008), and many users have become familiar with more complex technology interactions in everyday life (Walker et al. 2009), perceptions of ATM convenience and usability standards will also change (Hawk 2008), and there are potentially opportunities for larger-scale redesign in the future.

Some advanced features have been trialled by individual banks: for example, the Swedish bank SEB has installed talking ATMs which guide users through the transaction process (Betts 2007), similarly to the concept suggested by the 'Computers as social actors' pattern in Table 3. These are primarily aimed at users with impaired vision or reading ability; the idea is also mentioned by Chan et al (2009) in the context of improving ATM design for older users.

Each concept suggested has strengths and weaknesses, including the impact it could have on other elements of the system and users' interactions. A system emphasising the return of the ATM card could lead to users forgetting to retrieve their cash, or draw unwanted attention from passers-by. This is the sort of issue where specialist domain knowledge of user behaviour would be valuable, together with user trials of the concepts. Observing users' interactions with the machines (see Baber \& Stanton 1996) would no doubt suggest additional solutions, which could be captured by revisions to the DwI method. 


\section{Discussion and further work}

This article has described the Design with Intent Method and applied it to a 'user behaviour' problem to illustrate its use. The example is simple and the full range of real-world constraints has not been applied, but a set of pertinent design concepts has been generated, which could be developed further. It is arguable that most of the concepts suggested would be obvious to experienced human factors professionals, particularly those with interface design expertise, but as Stanton and Young (2003) note, design decisions about aspects of systems affecting human performance are often made "by people with no specialist training in ergonomics," and with variable success in applying and translating the recommendations of formal methods into product specifications (e.g. Kuijt-Evers et al. 2008).

\subsection{Limitations of this application}

It is essential to recognise a major limitation of the application of the DwI Method in this article: it was carried out by the authors, rather than independent designers, and the brief (section 3.1) related to a problem which is already 'solved' to a large extent (see discussion in section 3.2.4). In this sense, there is a significant risk of the concepts produced being 'engineered' to fit ideas which are already well-known with ATMs. Equally, the understanding of how to apply the design patterns suggested would differ for people untrained in the ideas behind them and unfamiliar with their development.

Bearing this in mind, the ATM example in this article should be viewed as simply a demonstration of how the DwI Method can be applied, rather than a test of its efficacy. This is a paper exercise carried out by the authors rather than by designers in an industrial context, and the utility and usability performance of the method in this latter situation is essential to its further development. With these caveats, it is difficult to assess the 'validity' of the results produced in the demonstration objectively, since there was no control condition; however, if treated as an idealised example of how to think about this sort of brief in a semi-structured way, it is hoped that the demonstration is of some use to designers working in this field.

\subsection{Further work}

This exercise ran alongside an research programme involving designer trials of DwI Method iterations to ascertain usefulness (compared with other concept generation methods) and improve usability of the method itself in the context of a user-centred design process (see section 2.1.3; Lockton et al 2009b). Taking into account these outcomes, the method will then be applied to real problems (as noted in section 1.3) within the field of influencing user behaviour with energy- or other resource-using products and services. Studying the practical effects of designs developed using the method, both technologically and in human factors terms, will be the most important test of the method's utility as a design tool. 
A subset of the design concepts suggested will be developed into working prototypes and comparative trials run with users to quantify the difference in resources used by designs over the trial period, compared with existing products. The human factors involved in the relative success or failure of the designs will be assessed alongside technological considerations, refining the DwI Method to incorporate evidence about the application of the techniques.

The intended outcome is a design tool that is useful, usable and applicable to a wide range of behaviour change problems, made available in a range of forms in which designers can apply it practically, including posters (as currently used for the inspiration mode; see section 2.1.1), method cards (e.g. as shown in Figure 4), and an online version (a basic implementation of which is currently available at designwithintent.co.uk ). The method could be 'learned' through applying it to a range of briefs and becoming more familiar with the patterns; it is possible that over time, an embodiment of the method would no longer be needed, as the ideas become part of a designer's repertoire.

Adding the DwI Method to the stock of human factors methods available to designers (e.g. Stanton et al. 2005) will enable techniques for influencing user behaviour to be considered in the early stages of the design process. Most commercial design is really redesign of one form or another (Michl 2002), and redesign intended to correct user error with an existing product or system is often where human factors techniques find application. If the DwI Method were applied at an early stage of the redesign process - as recommended for the use of ergonomics methods by Stanton and Young (2003) - a design team could be guided towards a set of applicable techniques right from the start. As behaviour change becomes more widely seen as part of the 'design' remit (e.g. Fabricant 2009), methods for incorporating these ideas into the design process have the potential to help designers explore problems they have not previously considered. 


\section{References}

Adams, P \& David, G 2007, "Light vehicle fuelling errors in the UK: The nature of the problem, its consequences and prevention.” Applied Ergonomics, vol. 38, pp. 499-511.

Akrich, M 1992, "The De-Scription of Technical Objects" in: Bijker, W, Law, J (eds.) Shaping Technology/Building Society, MIT Press, Cambridge, pp. 205-224.

Alexander, C, Ishikawa, S, Silverstein, M, Jacobson, M et al. 1977, A Pattern Language: Towns, Buildings, Construction, Oxford University Press, New York.

Altshuller, G 1996, And Suddenly the Inventor Appeared, Technical Innovation Center, Worcester.

Ariely, D 2008, Predictably Irrational, HarperCollins, London.

Baber, C \& Stanton, NA 1994, “Task analysis for error identification.” Ergonomics, vol. 37, pp. $1923-1942$.

Baber, C \& Stanton, NA 1996, "Human error identification techniques applied to public technology: predictions compared with observed use." Applied Ergonomics, vol. 27, no. 2, pp. 119-131.

Barker, RG 1968, Ecological Psychology, Stanford University Press, Stanford.

Barr, P, Noble, J \& Biddle, R 2002, “A Taxonomy of User Interface Metaphors," in Proceedings of SIGCHI-NZ Symposium On Computer-Human Interaction.

Beale, R 2007, "Slanty Design.” Communications of the ACM, vol. 50, no. 1, p. 21-24.

Beatty, PC 2008, "Designing Persuasive Technologies for Human Factors Engineering: An Alternative Classification to the Triad of Captology," in H Oinas-Kukkonen, PFV Hasle, M Harjumaa, \& K Segerstahl (eds), Persuasive 2008: Third International Conference on Persuasive Technology: Poster Proceedings, University of Oulu Press, Oulu, pp. 98--101.

Betts, B 2007, “Cash machines get a voice.” The Register. Retrieved January 9, 2009, from http://www.theregister.co.uk/2007/05/03/atms_talk_swedish/

Bhamra, T, Lilley, D \& Tang, T 2008, "Sustainable use: Changing Consumer Behaviour Through Product Design," in Changing the Change: Design Visions, Proposals and Tools, Turin, 2008, Proceedings.

Blackler, A, Popovic, V \& Mahar, D 2009, "Investigating users' intuitive interaction with complex artefacts," Applied Ergonomics in press, doi:10.1016/j.apergo.2009.04.010

Blevis, E 2007, “Sustainable Interaction Design: Invention \& Disposal, Renewal \& Reuse." in CHI 2007 Proceedings - Design Theory.

Buchanan, R 1985, "Declaration by Design: Rhetoric, Argument, and Demonstration in Design Practice." Design Issues, vol. 2, no. 1, p. 4-22.

Byrne, MD \& Bovair, S 1997, “A Working Memory Model of a Common Procedural Error.” Cognitive Science, vol. 21, no. 1, pp. 31--61. 
Cairns, P \& Cox, AL 2008, "Preface" to Cairns, P \& Cox, AL (eds.), Research Methods for HumanComputer Interaction, Cambridge University Press, Cambridge.

Carroll, JM, Kellog, WA \& Rosson, MB 1991, "The Task-Artifact Cycle,” in JM Carroll (ed), Designing Interaction: Psychology at the Human-Computer Interface, Cambridge University Press, London.

Chak, A 2003, Submit Now: Designing Persuasive Web Sites, New Riders, Indianapolis.

Chamorro-Koc, M, Popovic, V \& Emmison, M 2008, "Human experience and product usability: Principles to assist the design of user-product interactions." Applied Ergonomics, vol. 39, pp. $1--9$.

Chan, CC, Wong, AW, Lee, TM \& Chi, I 2009, "Modified automatic teller machine prototype for older adults: A case study of participative approach to inclusive design." Applied Ergonomics, vol. 40, pp. 151--160.

Chase, RB \& Stewart, DM 2002, Mistake-Proofing: Designing Errors Out (Revised Edition), Lulu Press/John Grout, Morrisville.

Chung, PH \& Byrne, MD 2008, "Cue effectiveness in mitigating postcompletion errors in a routine procedural task.” International Journal of Human-Computer Studies, vol. 66, pp. 217--232.

Cialdini, R 2003, "Crafting Normative Messages to Protect the Environment." Current Directions in Psychological Science, vol. 12, no. 4, p. 105-109.

Craig, S, Harrison, D, Cripps, A \& Knott, D 2008, "BioTRIZ Suggests Radiative Cooling of Buildings Can Be Done Passively by Changing the Structure of Roof Insulation to Let Longwave Infrared Pass.” Journal of Bionic Engineering, vol. 5, no. 1, pp. 55-66.

Crowe, TD 2000, Crime Prevention Through Environmental Design, $2^{\text {nd }}$ edition, ButterworthHeinemann, Boston.

Daily WTF 2008, “\$50 Cash Fast.” Retrieved December 2, 2008, from http://thedailywtf.com/Comments/50-Cash-Fast.aspx\#228433

Design Council, Department of Health, Buckle, P, Clarkson, P et al. 2003, Design for Patient Safety: A System-Wide Design-Led Approach to Tackling Patient Safety in the NHS, Design Council / Department of Health, London. Retrieved December 2, 2008, from http://wwwedc.eng.cam.ac.uk/medical/downloads/report.pdf

Dolan, L 2005, “Comment: He who has ears to hear, let him hear correctly" Daily Telegraph. Retrieved January 8, 2009, from http://www.telegraph.co.uk/finance/2907038/Comment-hewho-has-ears-to-hear-let-him-hear-correctly.html

Elias, EW, Dekoninck, EA \& Culley, SJ 2007, “The Potential for Domestic Energy Savings through Assessing User Behaviour and Changes in Design," in Ecodesign 2007: Fifth International Symposium on Environmentally Conscious Design and Inverse Manufacturing.

Fabricant, R 2009, “Behaving badly in Vancouver.” Design Mind, February 11 2009, Frog Design, San Francisco. Retrieved June 1, 2009, from http://designmind.frogdesign.com/blog/behaving-badly-in-vancouver.html 
Flanagan, M 2005, Using a cash machine: A NALA training guide for adult education tutors, National Adult Literacy Agency, Dublin.

Flemming, SAC, Hilliard A \& Jamieson GA 2008, "The Need for Human Factors in the Sustainability Domain." Proceedings of the Human Factors and Ergonomics Society $52^{\text {nd }}$ Annual Meeting, pp. 748-752.

Fogg, BJ 1999, "Persuasive Technologies." Communications of the ACM, vol. 42, no. 5, p. 27-29.

Fogg, BJ 2003, Persuasive Technology: Using Computers to Change What We think and Do, Morgan Kaufmann, San Francisco.

Freed, M \& Remington, R 2000, "Human-machine system design: When does simulation pay?," in ICCM 2000: Third International Conference on Cognitive Modeling: Proceedings, Groningen, Netherlands.

Gaver, WW 1991, "Technology Affordances," in CHI '91: Proceedings of the SIGCHI Conference on Human Factors in Computing Systems, ACM, New York, p. 79-84.

Gaver, WW 1992, "The Affordances of Media Spaces for Collaboration," in Computer Supported Cooperative Work 1992, Toronto, Proceedings, pp. 17-24.

Gibson, J 1986, The Ecological Approach to Visual Perception, Lawrence Erlbaum Associates, Hillsdale.

Grout, J 2007, Mistake-Proofing the Design of Health Care Processes, Agency for Healthcare Research and Quality, Rockville.

Hawk, T 2008, “Why Are ATM Machines So Stupid?.” Retrieved December 2, 2008, from http://thomashawk.com/2008/04/why-are-atm-machines-so-stupid.html

Hendrick, HW 2008, “Applying ergonomics to systems: Some documented "lessons learned"." Applied Ergonomics, vol. 39, pp. 418-426.

IDEO 2003, IDEO Method Cards: 51 Ways to Inspire Design, IDEO, Palo Alto.

Jones, E, Mann, D, Stanton, NA \& Harrison, D 2001, “An Eco-innovation Case Study of Domestic Dishwashing through the Application of TRIZ Tools." Creativity and Innovation Management, vol. 10, no. 1, p. 3-14.

Kahneman, D, Slovic, P \& Tversky, A (eds.) 1982, Judgment under Uncertainty: Heuristics and Biases, Cambridge University Press, Cambridge.

Kanis, H 1998, "Usage centred research for everyday product design.” Applied Ergonomics, vol. 29, no. 1, pp. $75-82$.

Katyal, NK 2002, “Architecture as Crime Control.” Yale Law Journal, 111, pp. 1039-1139.

Kjaer Christensen, A \& Hasle, PFV 2007, "Classical Rhetoric and a Limit to Persuasion," in Y de Kort, W IJsselsteijn, CJH Midden, B Eggen, \& BJ Fogg (eds), Persuasive Technology: Second International Conference, Persuasive 2007, Palo Alto, April 26-27, 2007, Proceedings, Springer, Berlin, pp. 307-310. 
Kolko, J 2007, Thoughts on Interaction Design, Brown Bear LLC, Savannah.

Kuijt-Evers, L, Morel, K, Eikelenberg, N \& Vink, P 2008, "Can the design team complete the House of Quality appropriately?.” Applied Ergonomics, in press doi:10.1016/j.apergo.2008.09.009.

Lane, RM, Stanton, NA \& Harrison, D 2006, “Applying hierarchical task analysis to medication administration errors.” Applied Ergonomics, vol. 37, no. 5, pp. 669--679.

Lilley, D, Lofthouse, V \& Bhamra, T 2005, “Investigating Product Driven Sustainable Use," in Sustainable Innovation '05 Conference, Farnham, Proceedings.

Lilley, D, Lofthouse, V \& Bhamra, T 2006, “Towards sustainable use: An exploration of designing for behavioural change," in L Feijs, S Kyffin, \& B Young (eds), DeSForM 2006: Design and semantics of form and movement,p. 84-97.

Lockton, D 2005, "Benches Archive." Design with Intent / Architectures of Control. Retrieved December 2, 2008, from http://architectures.danlockton.co.uk/category/benches/

Lockton, D, Harrison, D \& Stanton, NA 2008a, "Design with Intent: Persuasive Technology in a Wider Context," in H Oinas-Kukkonen, P Hasle, M Harjumaa, K Segerstahl, \& P Ohrstrom (eds), Persuasive Technology: Third International Conference, Persuasive 2008, Oulu, Finland, June 4-6, 2008, Proceedings, Springer, Berlin, p. 274-278.

Lockton, D, Harrison, D \& Stanton, NA 2008b, "Making the user more efficient: Design for sustainable behaviour." International Journal of Sustainable Engineering, vol. 1, no. 1, pp. $3-8$.

Lockton, D, Harrison, D \& Stanton, NA 2009a, Design for Behaviour Change: The Design with Intent Toolkit v.0.9, Brunel University, Uxbridge. Retrieved June 1, 2009, from http://designwithintent.co.uk

Lockton, D, Harrison, D, Holley, T \& Stanton, NA 2009b, "Influencing Interaction: Development of the Design with Intent Method," in Persuasive Technology: Fourth International Conference, Persuasive 2009, Claremont, California, Proceedings, ACM Digital Library, New York.

Lonsdale, P 2004, “Old problems still out there: Why do ATMs give you the card back first?." HCI Commentary. Retrieved January 8, 2009, from http://www.cs.bham.ac.uk/ rxb/Teaching/HCI/blog/2004/03/old-problems-still-out-therewhy-do.html

Matthews, G, Davies, DR, Westerman, SJ \& Stammers, RD 2000, “Human Error," in Human Performance: Cognition, stress and individual differences, Psychology Press, New York.

McCalley, LT \& Midden, CJH 2002, "Energy conservation through product-integrated feedback: The roles of goal-setting and social orientation." Journal of Economic Psychology, vol. 23, pp. 589--603.

McGrenere, J \& Ho, W 2000, “Affordances: Clarifying and Evolving a Concept," in Graphics Interface 2000, Montreal, Proceedings.

Michl, J 2002, “On Seeing Design as Redesign: An Exploration of a Neglected Problem in Design Education ." Scandinavian Journal of Design History, vol. 12, pp. 7--23. 
New York Times 1990, "Help for Forgetful Bank-Card Holders.” New York Times. Retrieved January 8, 2009, from http:/query.nytimes.com/gst/fullpage.html? res $=$ 9C0CE0DD1531F93AA1575AC0A966958260

Norman, D 1988, The Psychology of Everyday things, Basic Books, New York.

Norman, DA 1999, “Affordance, Conventions, and Design.” Interactions, p. 38-42.

Norman, D 2008, “Signifiers, Not Affordances.” Interactions, vol. 15, no. 6, pp. 18--19.

Ormerod, TC \& Shepherd, A 2004, "Using task analysis for information requirements specification: The SGT method," in D Diaper \& NA Stanton (eds), The Handbook of Task Analysis for Human-Computer Interaction, Lawrence Erlbaum Associates, Mahwah, pp. 347--365.

Redstrom, J 2006, "Persuasive Design: Fringes and Foundations," in W IJsselsteijn, Y de Kort, CJH Midden, B Eggen, \& E van den Hoven (eds), Persuasive Technology: First International Conference, Persuasive 2006, Eindhoven, May 18-19, 2006, Proceedings, Springer, Berlin, p. $112-122$.

Richardson, M 2008, "Ergonomists as Choice Architects: Behavioural Economics and Ergonomics." The Ergonomist, no. 458, pp. 1--2.

Rodriguez, E \& Boks, C 2005, "How design of products affects user behaviour and vice versa: the environmental implications," in Ecodesign 2005: Fourth International Symposium on Environmentally Conscious Design and Inverse Manufacturing.

Rogers, WA \& Fisk, AD 1997, “ATM Design and Training Issues.” Ergonomics in Design, pp. 4-9.

Rogers, WA, Fisk, AD, Mead, SE, Walker, N \& Cabrera, EF 1996, "Training Older Adults to Use Automatic Teller Machines.” Human Factors, vol. 38, no. 3, pp. 425--433.

Saffer, D 2005, “The Role of Metaphor in Interaction Design.” Thesis, Carnegie Mellon University.

Salovaara, A 2008, "Inventing New Uses for Tools: A Cognitive Foundation for Studies on Appropriation.” Human Technology, vol. 4, no. 2, pp. 209--228.

Schneier, B 2003, Beyond Fear, Copernicus Books, New York.

Seva, RR, Been-Lirn Duh, H \& Helander, MG 2007, "The marketing implications of affective product design.” Applied Ergonomics, vol. 38, pp. 723--731.

Shingo, S 1986, Zero Quality Control: Source Inspection and the Poka-Yoke System, Productivity Press, Portland.

Simon, HA 1969, The Sciences of the Artificial, MIT Press, Cambridge.

Slashdot 2006, "Would You Trust RFID-Enabled ATM Cards?." Retrieved December 2, 2008, from http://ask.slashdot.org/article.pl?sid=06/12/06/0532242

Slovic, P, Finucane, M, Peters, E \& MacGregor, D 2002, "The affect heuristic," in T Gilovich, D Griffin, \& D Kahneman (eds), Heuristics and Biases: The Psychology of Intuitive Judgment, Cambridge University Press, London, pp. 397--420. 
Sommer, R 1969, Personal Space: The Behavioral Basis of Design, Prentice-Hall, Englewood Cliffs.

Stanton, NA, Salmon, P, Walker, G, Baber, C \& Jenkins, D 2005, Human Factors Methods: A Practical Guide for Engineering and Design, Ashgate Pub. Co, Aldershot.

Stanton, NA 2006, "Hierarchical task analysis: Developments, applications, and extensions." Applied Ergonomics, vol. 37, pp. 55--79.

Stanton, NA \& Baber, C 1998a, "Designing for consumers: editorial.” Applied Ergonomics, vol. 29, no. 1, pp. 1--3.

Stanton, NA \& Baber, C 1998b, “A systems analysis of consumer products," in NA Stanton (ed), Human Factors in Consumer Products, Taylor \& Francis, London, pp. 75--90.

Stanton, NA \& Young, M 1998, "Is utility in the mind of the beholder? A study of ergonomics methods.” Applied Ergonomics, vol. 29, no. 1, pp. 41--54.

Stanton, NA \& Young, M 2003, "Giving ergonomics away? The application of ergonomics methods by novices.” Applied Ergonomics, vol. 34, pp. 479--490.

Stern, N 2007, Stern Review: The Economics of Climate Change, Cambridge University Press, Cambridge.

Thaler, RH \& Sunstein, CR 2008, Nudge: Improving Decisions About Health, Wealth, and Happiness, Yale University Press, New Haven.

Tidwell, J 2005, Designing Interfaces, O'Reilly, Sebastopol.

Walker, GH, Stanton, NA, Jenkins, DP \& Salmon, PM 2009, "From telephones to iPhones: Applying systems thinking to networked, interoperable products." Applied Ergonomics, vol. 40, pp. 206--215.

Wever, R, van Kuijk, J \& Boks, C 2008, “User-centred Design for Sustainable Behaviour." International Journal of Sustainable Engineering, vol. 1, no. 1, p. 9-20.

Williamson, M 2008, “Queen Of The Cash Machine.” The Herald. Retrieved January 9, 2009, from http://www.theherald.co.uk/business/news/display.var.2227538.0.Queen_of_the_cash_machi ne.php

Wood, G \& Newborough, M 2003, "Dynamic energy-consumption indicators for domestic appliances: environment, behaviour and design." Energy and Buildings, no. 35, p. 821-841.

Zimmerman, CM \& Bridger, RS 2000, "Effects of dialogue design on automatic teller machine (ATM) usability: transaction times and card loss." Behaviour \& Information Technology, vol. 19, no. 6, pp. $441-449$. 


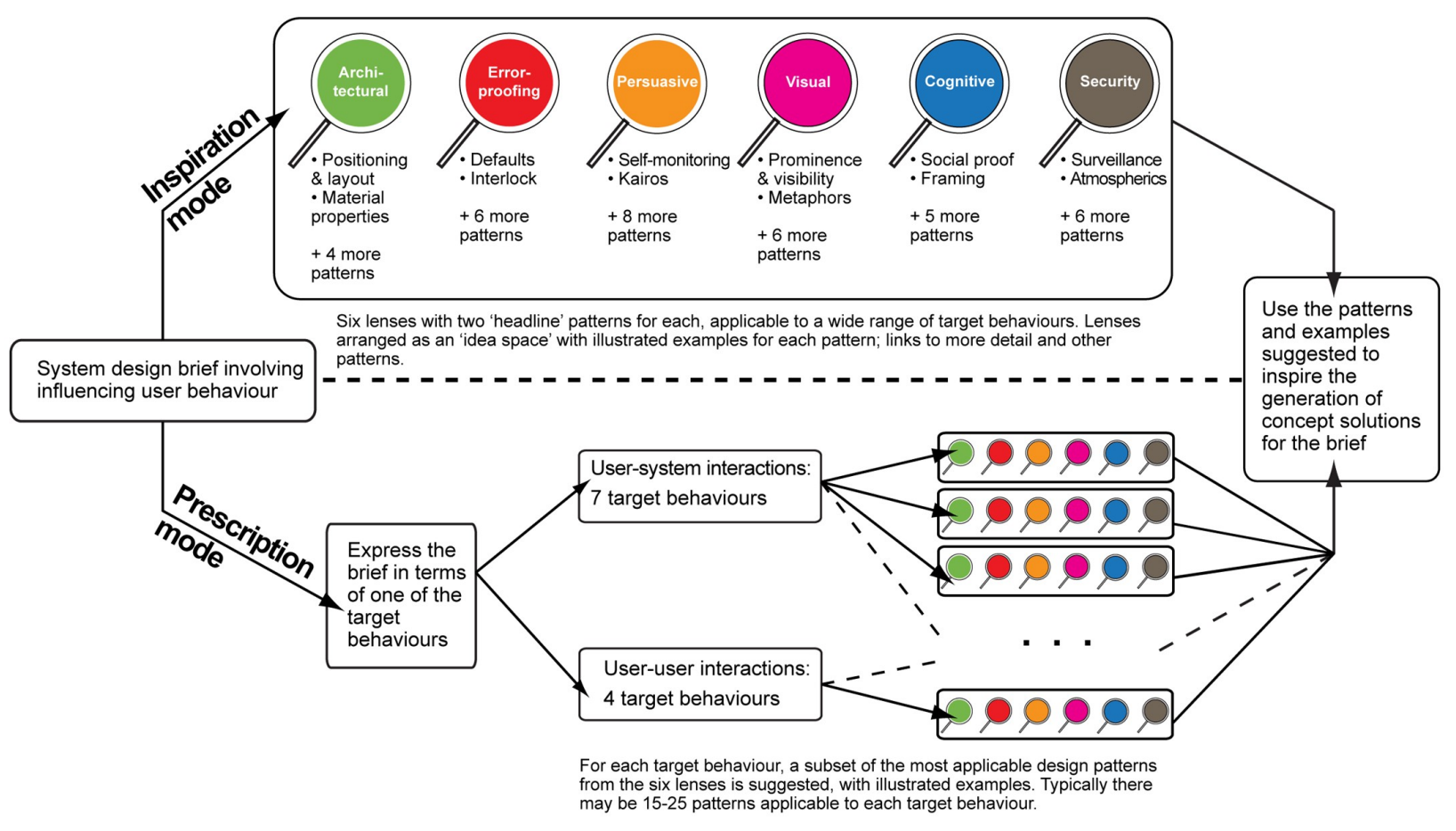

Fig. 1. The structure of the Design with Intent Method, with inspiration and prescription modes of use. 


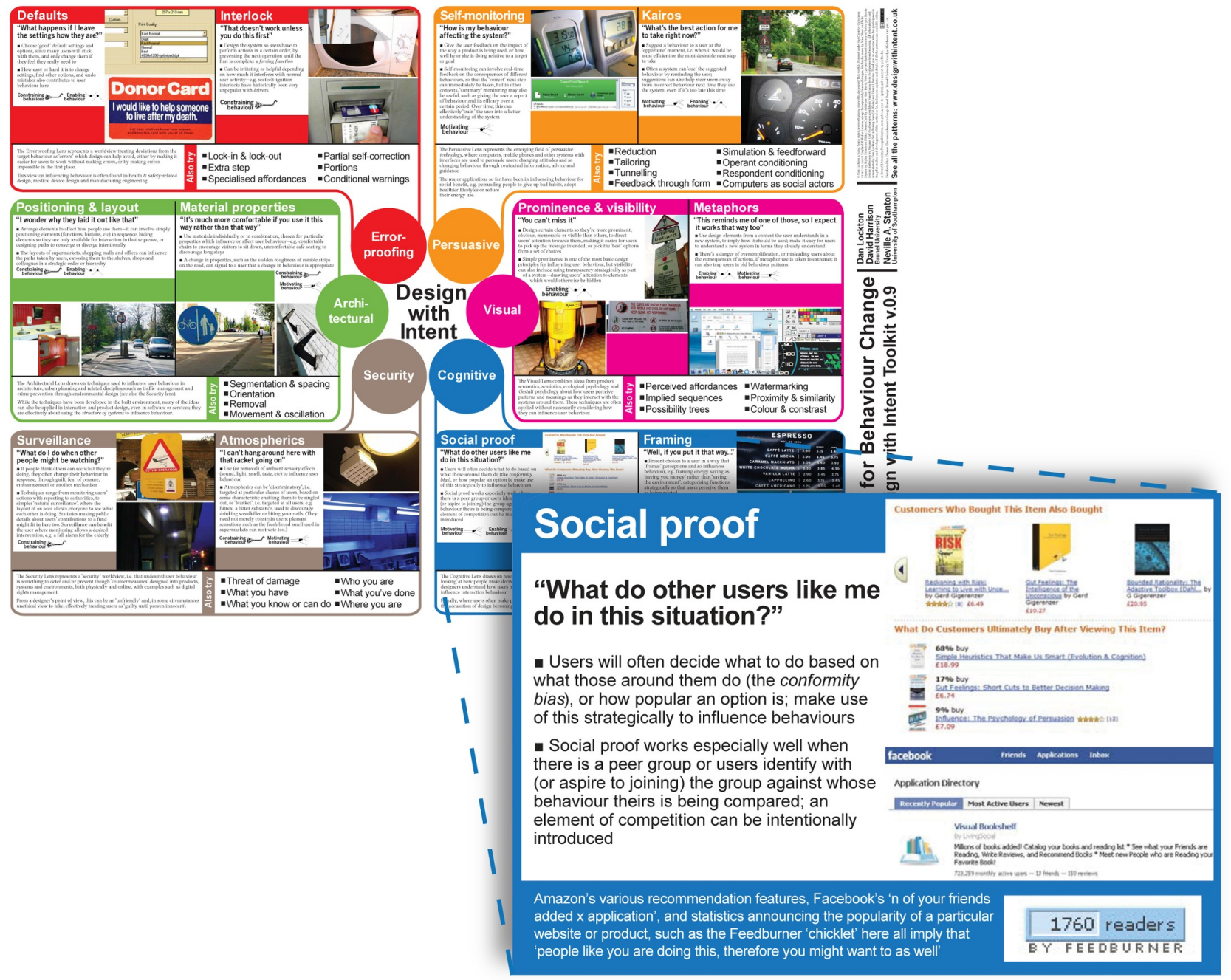

Fig. 2. The toolkit poster used for the inspiration mode, with a close-up of Social proof, one of the patterns.

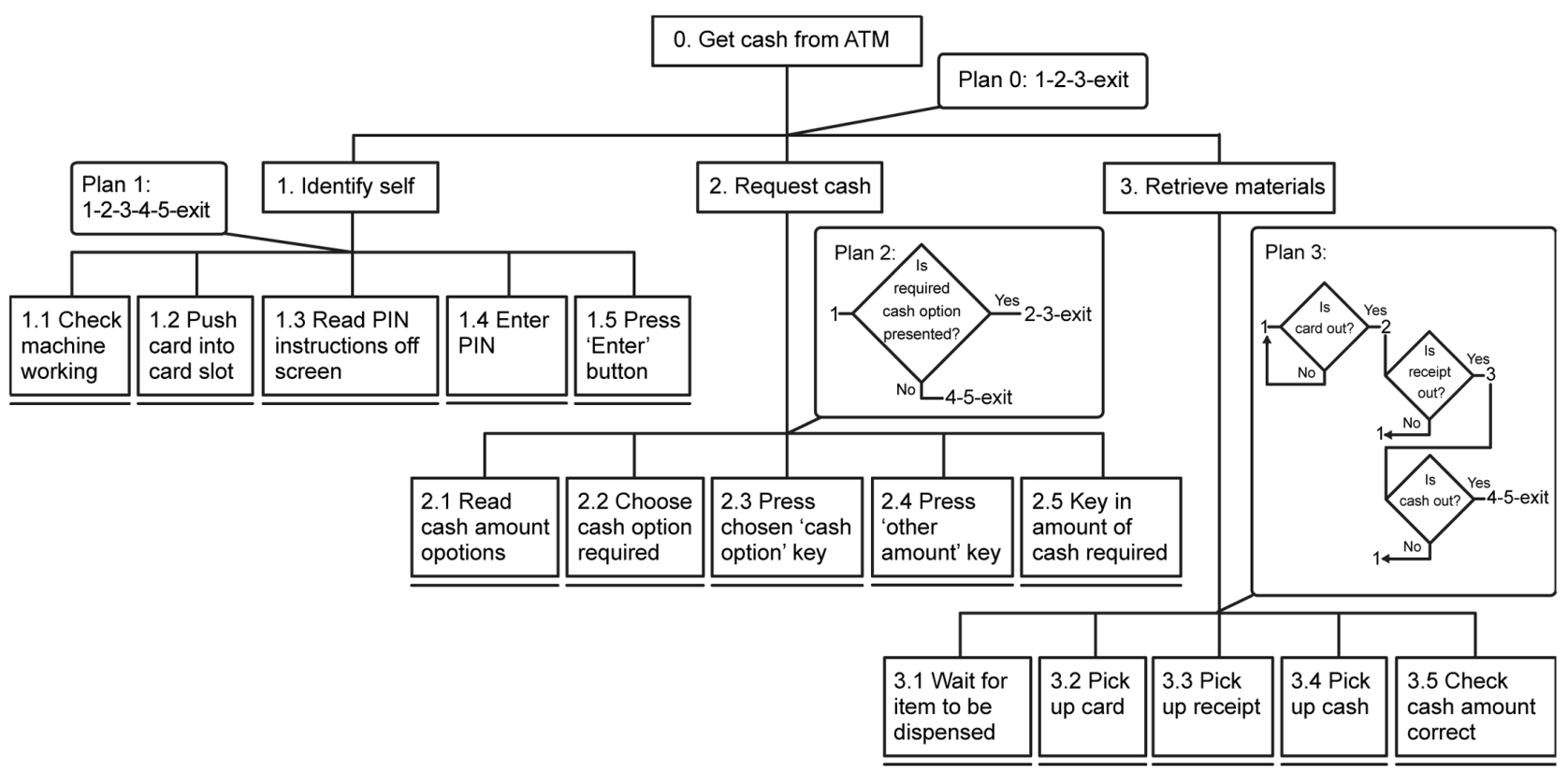

Fig. 3. HTA of the 'Get cash from ATM' goal for a typical modern ATM. 


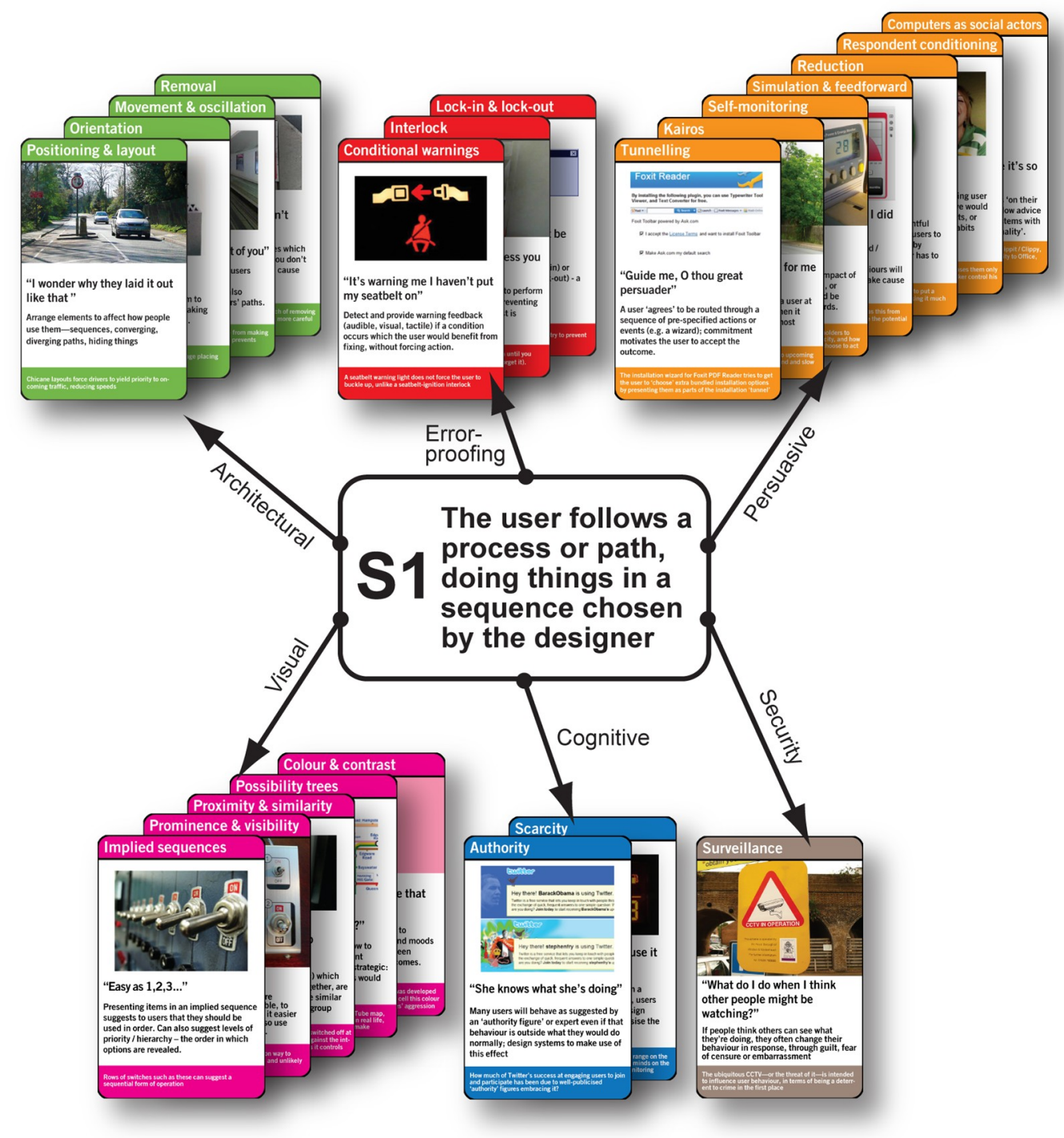

Fig. 4. Design patterns suggested for S1 target behaviour, in prescription mode.

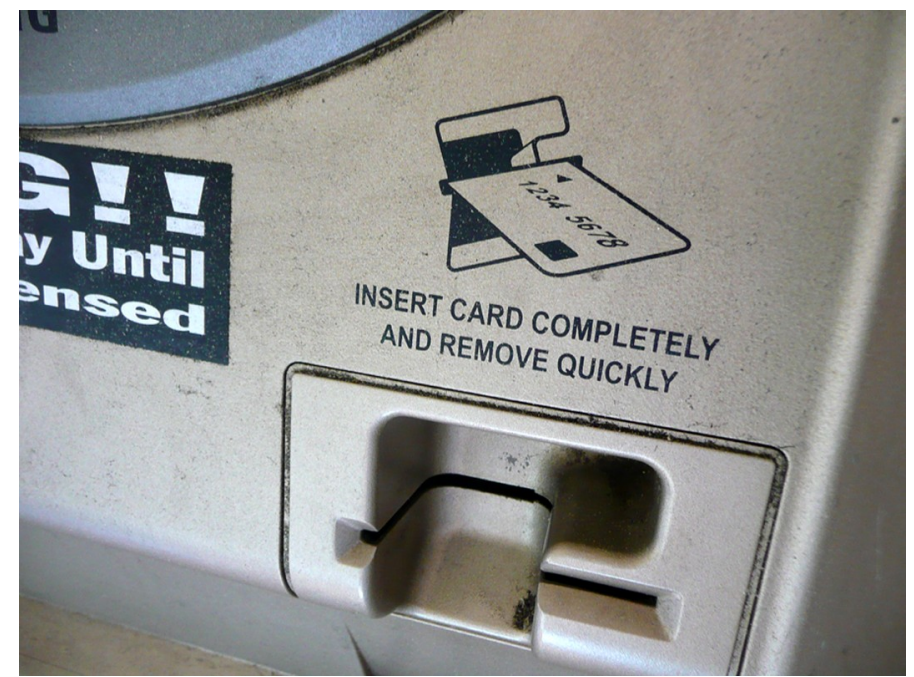

Fig. 5. An ATM in San Francisco requiring the user to insert and remove the card before beginning the transaction. 